\title{
Pengaruh Konsentrasi NaOH pada Sintesis Nanosilika dari Sinter Silika Mata Air Panas Sentral, Solok Selatan, Sumatera Barat dengan Metode Kopresipitasi
}

\author{
Hendro Susilo*, Ardian Putra, Astuti \\ Laboratorium Fisika Bumi, Jurusan Fisika, FMIPA, Universitas Andalas \\ Kampus Unand, Limau Manis, Padang, 25163 \\ *susilohendro71@yahoo.com
}

\begin{abstract}
ABSTRAK
Nanopartikel silika telah disintesis dari sinter silika yang bersumber dari mata air panas Sentral, Solok Selatan, Sumatera Barat menggunakan metode kopresipitasi. Sintesis dilakukan dengan cara merendam sinter silika dengan $\mathrm{HCl} 10 \mathrm{M}$ selama 12 jam dan direaksikan dengan $\mathrm{NaOH} 8 \mathrm{M}, 9 \mathrm{M}$ dan $10 \mathrm{M}$. Larutan disaring dan dititrasi dengan $\mathrm{HCl} 10 \mathrm{M}$ hingga $\mathrm{pH}$ mencapai 1, kemudian dicuci dan dikeringkan dengan oven selama 5 jam dengan suhu $100{ }^{\circ} \mathrm{C}$. Dari hasil karakterisasi X-Ray Diffraction (XRD) didapatkan bahwa sampel yang direaksikan dengan $\mathrm{NaOH} 8 \mathrm{M}$ dan $9 \mathrm{M}$, menghasilkan fasa kristal dengan ukuran kristal berturut-turut $224 \mathrm{~nm}$ dan $138 \mathrm{~nm}$, sedangkan sampel dengan konsentrasi $\mathrm{NaOH} 10 \mathrm{M}$ memiliki fasa amorf. Berdasarkan hasil karakterisasi Scanning Electron Microscopy (SEM) didapatkan ukuran partikel rata-rata berturut-turut $506 \mathrm{~nm}, 245 \mathrm{~nm}$, dan $202 \mathrm{~nm}$.
\end{abstract}

Kata kunci : nanopartikel, sinter silika, kristal, XRD, SEM

\section{ABSTRACT}

Silica nanoparticles have been synthesized from siliceous sinter sourced from Sentral hot spring, South Solok, West Sumatra using coprecipitation method. Synthesis was performed by immersing the siliceous sinter with $10 \mathrm{M} \mathrm{HCl}$ for 12 hours and treating it with $\mathrm{NaOH} 8 \mathrm{M}, 9 \mathrm{M}$ and $10 \mathrm{M}$. The solution was filtered and titrated with $10 \mathrm{M} \mathrm{HCl}$ until pH reaches 1, then washed and dried in oven for 5 hours by 100 ${ }^{\circ} \mathrm{C}$ temperature. The analysis of X-Ray Diffraction (XRD) on that samples, the ones treated with $8 \mathrm{M}$ and $9 \mathrm{M}$ of $\mathrm{NaOH}$ form crystal phase which have $224 \mathrm{~nm}$ and $138 \mathrm{~nm}$ of crystal size, respectively, while the last still remains amorf. Based on the characterization of Scanning Electron Microscopy (SEM), their consecutively particles sizes range $506 \mathrm{~nm}, 245 \mathrm{~nm}, 202 \mathrm{~nm}$.

Keywords : nanoparticles, siliceous sinter, crystal, XRD, SEM

\section{PENDAHULUAN}

Keberadaan sumber daya alam khususnya sumber daya mineral di muka bumi ini sangat melimpah. Salah satu sumber daya mineral yang berpotensi untuk dikembangkan adalah silika $\left(\mathrm{SiO}_{2}\right)$. Penggunaan silika semakin meningkat terutama dalam ukuran nanometer yang disebut juga dengan nanosilika. Nanosilika telah dimanfaatkan dalam berbagai bidang.

Sintesis silika memerlukan perlakuan khusus untuk sampai pada skala nanometer, yaitu menggunakan beberapa metode seperti metode sol-gel process, metode hydrothermal, metode alkali fusion dan metode kopresipitasi. Metode kopresipitasi merupakan salah satu metode sintesis senyawa anorganik yang didasarkan pada pengendapan lebih dari satu substansi secara bersama-sama ketika melewati titik jenuhnya. Kopresipitasi merupakan metode yang menjanjikan karena prosesnya menggunakan temperatur rendah sehingga waktu yang dibutuhkan relatif lebih singkat, yaitu sekitar 12 jam. Beberapa zat yang paling umum digunakan sebagai zat pengendap dalam kopresipitasi adalah hidroksida, karbonat, sulfat dan oksalat (Rio, 2011) dan juga merupakan metode paling sederhana dan mudah dilakukan.

Silika terbentuk dari hasil pelapukan batuan yang mengandung mineral utama, seperti kuarsa dan feldspar, yang berwujud bubuk putih. Silika merupakan senyawa yang tidak reaktif dan hanya dapat dilarutkan dalam asam kuat, contohnya dengan menggunakan asam klorida $(\mathrm{HCl})$. Silika mempunyai tiga bentuk kristal yaitu quartz, cristobalite dan trydimite (Hadi, dkk., 2011).

Nanopartikel silika memiliki beberapa sifat diantaranya: luas permukaan besar, ketahanan panas yang baik, kekuatan mekanik yang tinggi dan elastisitasnya rendah (Kalapathy, dkk., 2000). Nanopartikel silika dapat digunakan sebagai prekursor katalis, adsorben dan filter komposit (Kalapathy, dkk., 2000). Nanosilika juga memiliki efek yang signifikan terhadap 
kekuatan mikrostruktur geopolimer (Deb, 2015), sifat tarikan, tekanan dan geseran pada komposit epoksi resin (Chira, 2016).

Berdasarkan penelitian yang telah dilakukan Hayati dan Astuti (2015) didapatkan hasil karakterisasi X-Ray Diffractometer (XRD) sintesis dengan NaOH 5 M mempunyai fasa amorf, sedangkan fasa kristal ditemukan pada sampel dengan konsentrasi $\mathrm{NaOH} 6 \mathrm{M}$ dan $7 \mathrm{M}$, menghasilkan ukuran kristal lebih kecil dari $50 \mathrm{~nm}$, memiliki bentuk dan ukuran partikel yang bervariasi antara $25 \mathrm{~nm}$ sampai $80 \mathrm{~nm}$. Endhovani dan Putra (2015) telah mengambil sampel sinter silika yang terdapat di sekitar sumber mata air panas Sentral di daerah Sapan Maluluang, Kabupaten Solok Selatan, dan berdasarkan hasil karakterisasi X-Ray Flouresence (XRF), yang terdapat di sekitar sumber mata air panas kandungan silika tertinggi dihasilkan sebesar 87,42\% dan $89,33 \%$. Berdasarkan hasil penelitian tersebut Putra dkk. (2015), melakukan sintesis nanopartikel silika pada 4 sampel silika yang diambil dari lokasi tersebut, dan berdasarkan hasil XRD 3 sampel memiliki fasa kristal dengan ukuran rata-rata 15,39 nm, dengan ukuran terbesar $21,08 \mathrm{~nm}$. Satu sampel yang lain menghasilkan fasa amorf.

Pada penelitian ini akan dilakukan sintesis nanosilika dari sinter silika mata air panas Sentral, Kabupaten Solok Selatan. Dengan memvariasikan konsentrasi $\mathrm{NaOH}$ yaitu 8 M, 9 M dan $10 \mathrm{M}$ dengan suhu $100{ }^{\circ} \mathrm{C}$ menggunakan metode kopresipitasi.

\section{METODE}

Peralatan yang digunakan dalam penelitian ini adalah gelas ukur, pipet spatula logam, corong kaca, cawan keramik, lumpang, kertas saring, kertas ph, timbangan digital, oven, ayakan 200 mesh. Sedangkan bahan yang digunakan adalah sinter silika, aquades, $\mathrm{HCl} 10 \mathrm{M}$ dan $\mathrm{NaOH} 8 \mathrm{M}, 9 \mathrm{M}, 10$ M. Sampel sinter silika diambil dari sumber mata air panas Sentral, Solok Selatan, Sumatera Barat.

Sinter silika digerus dan diayak menggunakan ayakan 200 mesh, dan $6 \mathrm{~g}$ hasil ayakan disintesis menggunakan metode kopresipitasi, dengan langkah-langkah sebagai berikut: sampel sinter silika direndam dalam $\mathrm{HCl} 10 \mathrm{M}$ selama 12 jam untuk melarutkan senyawa pengotor yang terkandung pada sampel. Selanjutnya sampel dicuci dengan aquades untuk memurnikannya kembali dan dikeringkan dengan oven. Hasil yang terbentuk direaksikan dengan memvariasikan konsentrasi $\mathrm{NaOH} 8 \mathrm{M}, 9 \mathrm{M}$ dan $10 \mathrm{M}$ kemudian disaring menggunakan kertas saring. Larutan yang dihasilkan dititrasi sedikit demi sedikit dengan $\mathrm{HCl}$ dengan mengontrol sampai $\mathrm{pH}$ mendekati 1. Hasil titrasi dicuci dengan aquades untuk menghilangkan $\mathrm{NaCl}$. Sampel dikeringkan dengan oven pada temperatur $100{ }^{\circ} \mathrm{C}$ selama 5 jam. Setelah kadar air hilang, dilakukan penggerusan dengan lumpang sehingga didapatkan serbuk.

Serbuk yang telah disintesis dikarakterisasi menggunakan XRD (X-Ray Diffractometer) dan SEM (Scanning Electron Microscope) untuk mengetahui struktur kristal, ukuran kristal, sebaran partikel dan morfologi permukaan nanosilika yang terbentuk.

\section{HASIL DAN DISKUSI}

\subsection{Struktur dan Ukuran Kristal}

Pengujian sampel silika menggunakan XRD dilakukan untuk mengetahui informasi tentang struktur dan ukuran kristal. Hasil karakterisasi XRD dapat dilihat pada Gambar 1, 2 dan 3 untuk konsentrasi $\mathrm{NaOH} \mathrm{8,9} \mathrm{dan} 10 \mathrm{M}$. Hasil XRD tersebut dicocokkan dengan data ICCD (International Centre for Diffraction Databese) dengan kode referensi yang berbeda untuk masing-masing sampel.

Dari Gambar 3 dapat dilihat bahwa tidak ditemukan puncak difraksi yang mengindikasikan sampel tersebut berada fasa amorf. Fasa amorf mempunyai atom-atom yang terbentuk tidak beraturan. Fasa amorf terjadi karena tingginya konsentrasi $\mathrm{NaOH}$ yang direaksikan dengan HCL sehingga terjadinya kesetimbangan reaksi kimia dan mengakibatkan struktur atom tidak berubah dan tetap tidak beraturan. 


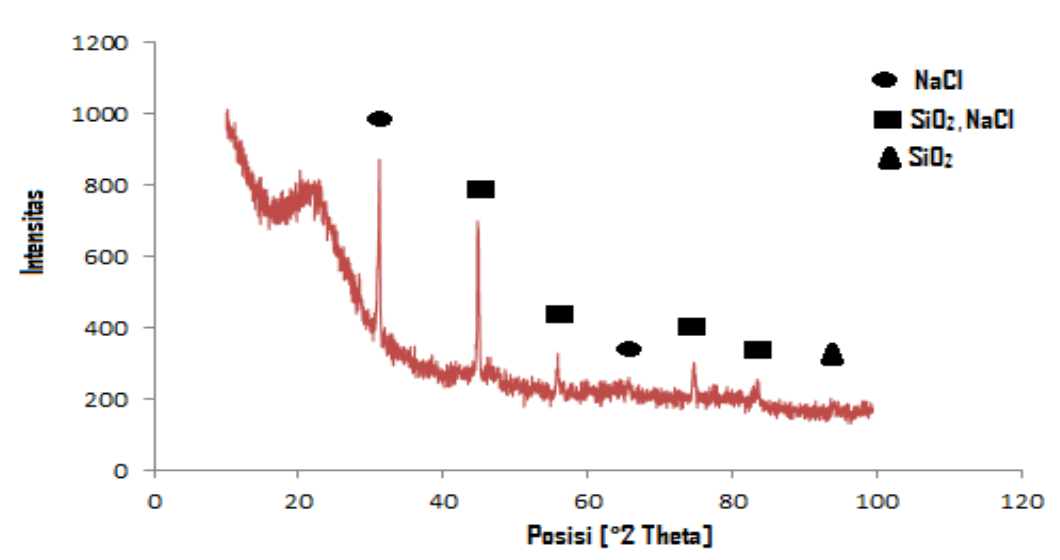

Gambar 1 Hasil XRD sampel A (NaOH $8 \mathrm{M})$.

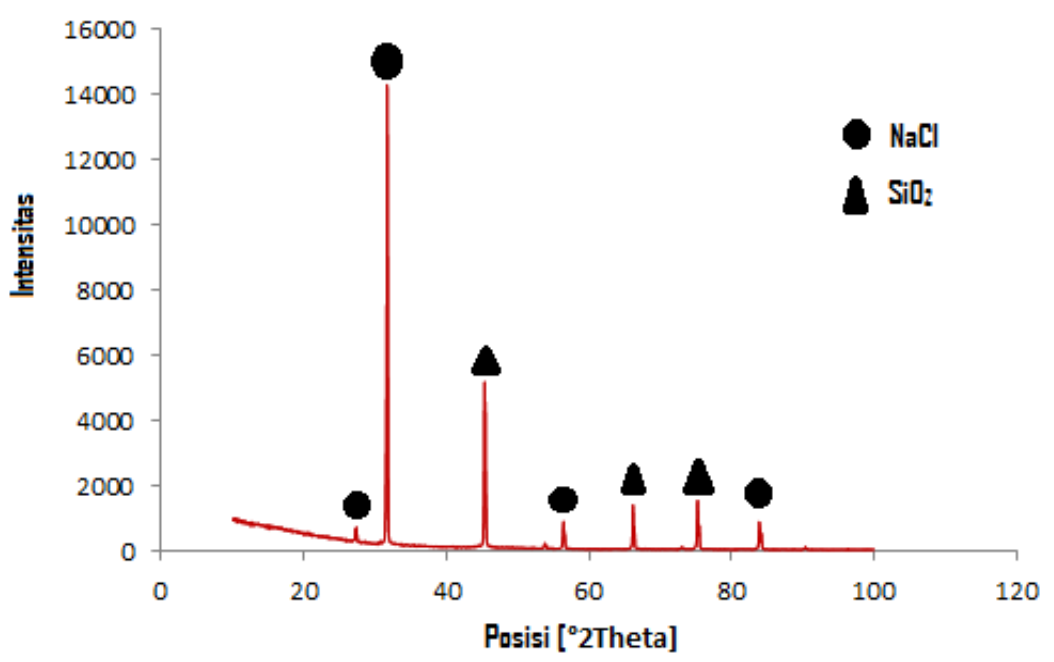

Gambar 2 Hasil XRD sampel B (NaOH 9 M)

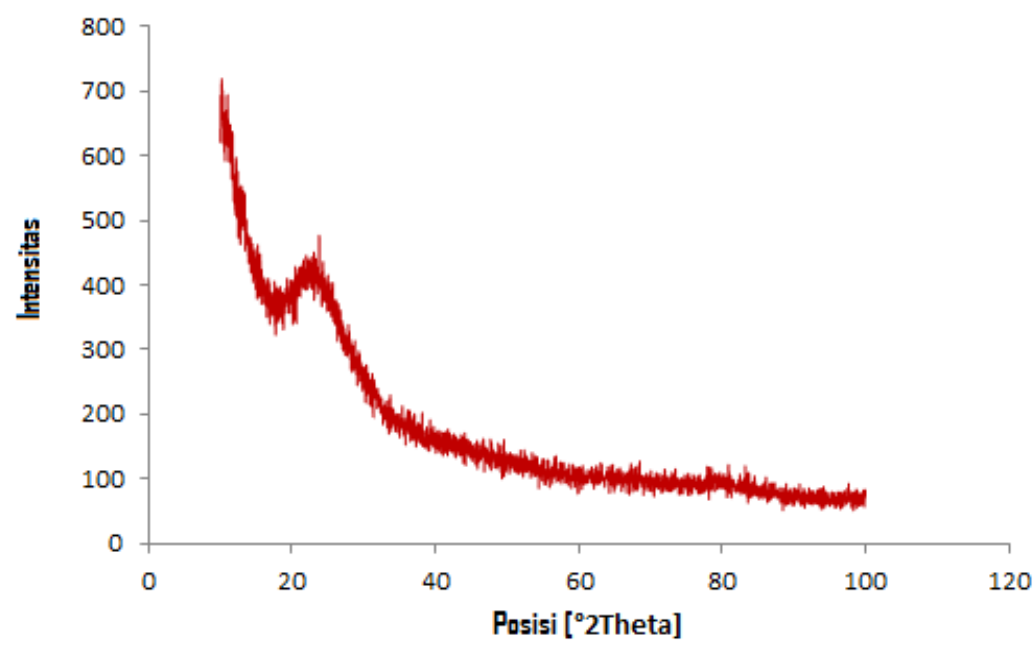

Gambar 3 Hasil XRD sampel C (NaOH 10 M)

Hasil perhitungan ukuran kristal dari silika menggunakan variasi konsentrasi $\mathrm{NaOH} 8$ $\mathrm{M}$ dan $9 \mathrm{M}$ dapat dilihat pada Tabel 1. Dari tabel dapat dilihat bahwa ukuran kristal silika yang didapatkan $\geq 100 \mathrm{~nm}$. Pada sampel A ukuran kristal silika adalah $224 \mathrm{~nm}$ dan sampel B ukuran 
kristal silika adalah $138 \mathrm{~nm}$, sedangkan sampel $\mathrm{C}$ tidak dapat dihitung karena berada pada fasa amorf.

Tabel 2 Ukuran kristal silika dengan konsentrasi $\mathrm{NaOH} 8 \mathrm{M}, 9 \mathrm{M}$ dan $10 \mathrm{M}$

\begin{tabular}{lcccc}
\hline Sampel & Konsentrasi NaOH $(\mathbf{M})$ & $\boldsymbol{B}(\mathbf{r a d})$ & $\boldsymbol{\theta}\left({ }^{\circ}\right)$ & $\boldsymbol{D}(\mathbf{n m})$ \\
\hline $\mathrm{A}$ & 8 & 0,0006699 & 22,73 & 224 \\
$\mathrm{~B}$ & 9 & 0,0010885 & 22,68 & 138 \\
$\mathrm{C}$ & 10 & - & - & - \\
\hline
\end{tabular}

Berdasarkan karakterisasi menggunakan XRD dapat disimpulkan bahwa adanya pengaruh konsentrasi $\mathrm{NaOH}$ terhadap banyaknya orientasi kristal. Peningkatan konsentrasi $\mathrm{NaOH}$ dari $8 \mathrm{M}$ ke $9 \mathrm{M}$ membuat bertambahnya puncak-puncak difraksi pada silika, sedangkan pada konsentrasi $\mathrm{NaOH} 10 \mathrm{M}$ terjadi fasa amorf yaitu susunan atomnya tidak teratur dalam rangkaiannya yang pendek. Pengaruh peningkatan konsentrasi $\mathrm{NaOH}$ terhadap ukuran kristal silika adalah semakin besar konsentrasi $\mathrm{NaOH}$ semakin kecil ukuran kristal silika yang didapatkan.

\subsection{Sebaran dan Morfologi Permukaan Silika}

Hasil karakterisasi SEM dengan variasi konsentrasi $\mathrm{NaOH} 8 \mathrm{M}, 9 \mathrm{M}$ dan $10 \mathrm{M}$ dapat dilihat pada Gambar 4. Dari Gambar 4a terlihat bahwa sebaran partikel silika lebih seragam (homogen), memiliki ukuran partikel bervariasi antara $242 \mathrm{~nm}-891 \mathrm{~nm}$ dengan rata-rata ukuran partikel sebesar $506 \mathrm{~nm}$. Morfologi permukaan sampel silika lebih dominan berbentuk bulat. Dari Gambar 4b terlihat bahwa sebaran partikel silika tidak seragam (heterogen), memiliki ukuran partikel bervariasi antara $150 \mathrm{~nm}-620 \mathrm{~nm}$ dengan rata-rata ukuran partikelnya sebesar $245 \mathrm{~nm}$. Morfologi permukaan sampel silika mempunyai bentuk yang bervariasi dari bentuk kubus sampai bulat. Dari Gambar 4c terlihat bahwa sebaran partikel silika tidak seragam (heterogen), memiliki ukuran partikel bervariasi antara $40 \mathrm{~nm}-340 \mathrm{~nm}$ dengan rata-rata ukuran partikelnya sebesar $202 \mathrm{~nm}$. Morfologi permukaan sampel silika lebih dominan berbentuk bulat. Sebagian besar partikel-partikel bulat kecil tersebut cenderung berikatan membentuk ikatan atau gumpalan-gumpalan partikel bulat besar atau yang disebut juga aglomerasi.

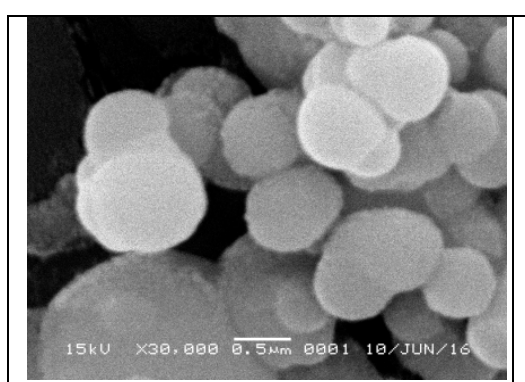

(a)

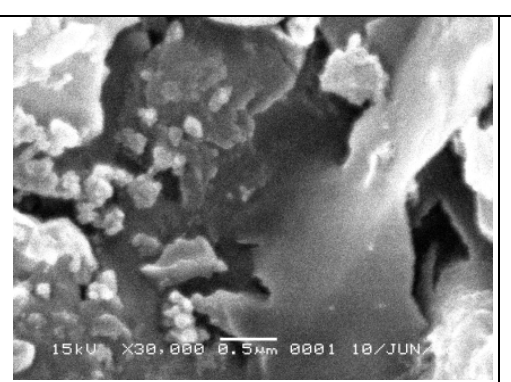

(b)

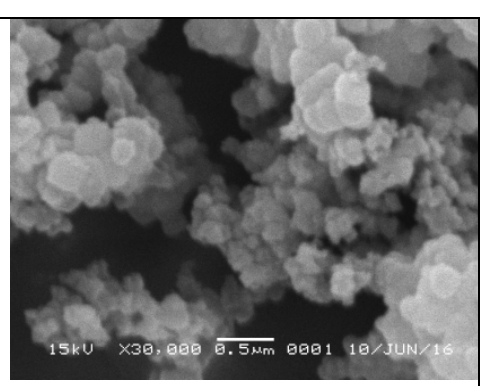

(c)

Gambar 4 Hasil SEM sebaran dan morfologi permukaan nanosilika perbesaran 30.000x menggunakan konsentrasi (a) $\mathrm{NaOH} 8 \mathrm{M}$ (b) $\mathrm{NaOH} 9 \mathrm{M}$ (c) $\mathrm{NaOH} 10 \mathrm{M}$

Rata-rata ukuran partikel masing-masing sampel dapat dilihat pada Tabel 2. Berdasarkan perhitungan dari hasil SEM dapat disimpulkan bahwa dengan penambahan konsentrasi $\mathrm{NaOH}$ menyebabkan penurunan ukuran partikel silika, tetapi membentuk gumpalangumpalan antara partikel (aglomerasi).

Tabel 3 Rata-rata ukuran partikel masing-masing sampel

\begin{tabular}{lcc}
\hline Sampel & $\begin{array}{c}\text { Konsentrasi NaOH } \\
(\mathbf{M})\end{array}$ & $\begin{array}{c}\text { Rata-rata Ukuran Partikel } \\
(\mathbf{n m})\end{array}$ \\
\hline $\mathrm{A}$ & 8 & 506 \\
$\mathrm{~B}$ & 9 & 245 \\
$\mathrm{C}$ & 10 & 202 \\
\hline
\end{tabular}




\section{KESIMPULAN}

Berdasarkan hasil sintesis dan karakterisasi silika dengan variasi konsentrasi $\mathrm{NaOH}$ dapat disimpulkan bahwa, dari hasil karakterisasi XRD diketahui bahwa terjadinya pembentukan fasa kristalin (struktur kristal) pada konsentrasi NaOH $8 \mathrm{M}$ ke $9 \mathrm{M}$, sedangkan pada konsentrasi $10 \mathrm{M}$ terjadi fasa amorf. Ukuran kristal pada konsentrasi $\mathrm{NaOH} 8 \mathrm{M}$ sebesar $224 \mathrm{~nm}$, sedangkan pada konsentrasi $\mathrm{NaOH} 9 \mathrm{M}$ sebesar $138 \mathrm{~nm}$. Dari karakterisasi SEM didapatkan ukuran partikel pada konsentrasi $\mathrm{NaOH} 8 \mathrm{M}$ bervariasi antara $242 \mathrm{~nm}-891 \mathrm{~nm}$, pada konsentrasi $9 \mathrm{M}$ didapatkan ukuran partikel antara $150 \mathrm{~nm}-620 \mathrm{~nm}$, sedangkan pada konsentrasi 10 M didapatkan ukuran partikel antara $40 \mathrm{~nm}-340 \mathrm{~nm}$.

\section{DAFTAR PUSTAKA}

Chira, A., Kumar, A., Vlach, T., Laiblova, L., Skapin, A.S., Hajek, P., 2016, Property improvement of alkali resistant glass fibres/epoxy composite nanosilica for textile reinforced concrete applications, Materials \& Design, 89(5), 146-155.

Deb, P.S., Sarker, P.K., Barbhuiya, S., 2015, Effects of nano-silica on the strength development

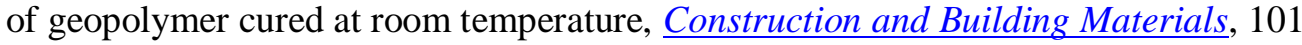
(1), 675-683.

Endhovani, R., dan Putra, A., 2015, Analisis Konduktivitas Termal dan Porositas Sinter Silika Sumber Mata Air Panas di Sapan Maluluang, Kecamatan Alam Pauh Duo, Kabupaten Solok Selatan, Jurnal Fisika Unand, Padang.

Hadi, S., Munasir., Triwikantoro., 2011, Sintesis Silika Berbasis Pasir Alam Bancar menggunakan Metode Kopresipitasi, Jurnal Fisika dan Aplikasinya, Vol. 7, No 2, Jur. Fisika ITS.

Hayati, R., dan Astuti, 2015, Sintesis Nanopartikel Silika Dari Pasir Pantai Purus Padang Sumatera Barat Dengan Metode Kopresipitasi, Jurnal Fisika Unand, 4 (3), 282-287.

Kalapathy., Proctor, A., Shultz, J., 2000, A Simple Method For Production of Pure Silica From Rice Hull Ash, Bioresource Technology. Vol.73, hal. 257-262.

Putra, A., Astuti, Susilo, H., Rhomar, Z., Endhovani, R., Nugroho, E.B., 2015, Sintesis Nanopartikel Silika dari Sinter Silika Mata Air Panas Sentral, Solok Selatan, Sumatera Barat Menggunakan Metode Kopresipitasi, Prosiding Seminar Nasional Fisika (SNF), Mataram.

Rio, B.F., 2011, Sintesis Nanopartikel $\mathrm{SiO}_{2}$ Menggunakan Metode Sol-Gel dan Aplikasinya Terhadap Aktifitas Sitotoksik, Jurnal Nanoteknologi, UNAND, Padang.

Smallman, R.E., dan Bishop, R.J., 1999, Metalurgi Fisik Modren dan Rekayasa Material, Edisi Keenam, Erlangga, Jakarta. 